\title{
Teatro Cientifico: O Lúdico para o Ensino e Aprendizagem de Química
}

\section{Science Theater: For Teaching and Learning Chemistry}

\begin{abstract}
Lizandra Alves de Oliveira; (Graduanda em Química na Universidade do Estado do Rio Grande
\end{abstract} do Norte - UERN)

Isadora Regina Galdino da Silva; (Graduanda em Química na Universidade do Estado do Rio Grande do Norte - UERN)

Lindeberg Ventura de Sousa*(Supervisor do PIBID de Química da Universidade do Estado do Rio Grande do Norte - UERN)

*LizandraAlvesStyles@outlook.com

\section{RESUMO}

O presente trabalho tem como objetivo apresentar as experiências das atividades do grupo QuíMistura transmitidas através do teatro científico para alunos do ensino do médio da escola Centro de Educação Integrada Professor Eliseu Viana (CEIPEV) cuja primeira experiência de cena foi vivida no Congresso de Teatro Cientifico que foi o IX Ciência em Cena. Como discussões das peças o ensino da química de forma lúdica através da improvisação, criatividade e experimentos.

O grupo de teatro QuíMistura, composto por alunos do ensino médio, utilizou da arte cênica para conceituar e discutir A Combustão. O grupo de teatro busca ensinar química por meio de peças teatrais baseada em obras literária. A companhia de teatro QuíMistura tem desenvolvido atividade interdisciplinar no Programa Institucional de Bolsa de Iniciação a Docência (PIBID) nas escolas estaduais, e teve uma efetiva participação no IX Ciência em Cena, a qual será relatada neste trabalho.

Palavras Chave: Teatro Científico; Ensino da Química; IX Ciência em Cena.

\section{ABSTRACT}

This study aims to present the experiences of quimistura group activities transmitted trough the scientific theater for high school students school teacher integrated Education Center Eliseu Viana (CEIPEV) whose first stage experience was lived in Scientific Theater of Congress was the IX Science on Stage. With the discussions of the pieces the teaching of chemistry in a playful way trough improvisation, creativity and experiments.

The quimistura theater group, composed of high school students, used the scenic art to conceptualize and discuss Combustion. The theater group seeks to teach chemistry trough plays based on literary works. The Quimistura theater company has developed interdisciplinary activity in the institutional Program Initiation Grant to Teaching (PIBID) in state school, and hand an effective participation in the IX Science on Stage, witch will be reported in the study.

Keywords: Scientific Theater; Chemistry Teaching; IX Science on Stage; 


\section{Introdução}

Despertar o interesse do aluno pela disciplina de química vem sendo uns dos desafios dos professores, e a mesma é conhecida pelos alunos como uma disciplina difícil, dogmática e bastante complexa pelo fato de lidar com números, regras, fórmulas e teoria. E para quebrar esse paradigma, partindo da explanação de dificuldade dos alunos o PIBID/QUÍMICA UERN inseriu o lúdico por meio do teatro como forma de ensino-aprendizagem. Tendo como presente iniciativa desenvolver na escola Centro de Educação Integrada Professor Eliseu Viana o ensino de química através do Teatro Cientifico.

O teatro cientifico, tem como finalidade divulgar o conhecimento através de peças teatrais visando uma evolução para uma educação interdisciplinar. Os texto das peças tende a passar conhecimento de uma forma didática e lúdica para um bom desenvolvimento do aluno. Segundo Douglas (2010), o teatro se torna uma ferramenta adequada para a reflexão, um espaço onde perguntas podem ser feitas (na apresentação de diversos pontos de vista), sem a necessidade de se oferecer as respostas, possibilitando ao público um espaço de reflexão.

Segundo Saraiva apud Montenegro: O Teatro tem todas as potencialidades para ser encarado como um veículo transmissor de conceitos científicos, através do qual a aprendizagem é feita de uma forma simples, lúdica e agradável. Para além disso, o teatro, se levado a cabo nas escolas, possibilita o desenvolvimento pessoal, permite ampliar o espírito crítico e o exercício da cidadania.

O QuíMistura foi criado a partir de um grupo de Teatro da Escola CEIPEV em 2013 cujo nome era Macunaíma, após uma participação no Ciência em Cena no Maranhão, coordenado por Lindeberg Ventura e por uma bolsista Ravana Rany Marques Batalha do PIBID. A primeira peça do grupo apresentada já com o nome QuíMistura foi O Tribunal, com finalidades de passar em cenas o que foi aprendido em sala de aula. Partindo da formação do grupo foi desenvolvido oficinas em sua segunda peça que se chamava A História Química de Uma Vela, todas as oficinas consistiam em representar expressões corporais, criatividade, improviso.

\subsection{Metodologia}

\subsection{A Química no Teatro}

"No caso da disciplina de Química, ao longo de muitos anos, na maioria dos casos, esta disciplina foi ensinada de forma dogmática, carregada de regras, fórmulas e informações para decorar e aplicar. Se é frequente ouvir-se dizer que a Química é uma disciplina difícil, o ensino da mesma tem de levar isso em consideração. Os professores de Química deparam-se diariamente com alunos desmotivados, que encaram esta disciplina como uma ciência teórica, praticamente inacessível, pouco ligada ao quotidiano; algo muito sério, que só interessa aos "cientistas" e onde o prazer de saber, a alegria de conhecer e o humor não têm lugar. (SARAIVA, 2007 p. 16).

Para os estudantes de química a disciplina não se relaciona com o cotidiano, sendo de modo difícil a sua relação com teoria e prática ao estudante de química. Tendo seus estudos levadas somente ao laboratório o estudante cria para si o conceito da relação teoria e praticidade, mas não associa aquele experimento ao seu cotidiano. Levando em conta que as suas atividades deve ser associada ao laboratório e ao cotidiano do aluno, mostrando que muitos dos experimentos são comuns do dia a dia e tornando assim de fácil entendimento.

Ao que se refere à disciplina de química não podemos fazer muito caso sobre a sua forma de aplicação, pois, muitos dos professores se acomodam a sua forma de ensino, sendo somente sua companhia um lápis e um quadro branco. Mudar a forma de aplicá-la aos alunos em sala de aula tentando causar nem que seja o mínimo de impacto com a novidade ao 
estudante. Uma aula lúdica seria uma inovação no ensino da química e aos próprios estudantes da disciplina.

Assim sendo, temos o Teatro Cientifico como inovação e ludicidade para melhor representar o ensino-aprendizagem da disciplina, utilizando também oficinas de artes cênicas como recurso metodológico. Para uma melhor aprendizagem houve alguns experimentos feitos em cena envolvendo a combustão, os experimentos feitos foram o copo sob a vela onde a chama se apaga, e o da palha de aço.

\subsection{Oficinas de Teatro}

Oficinas antes de qualquer peça tem uma grande importância, pois, dá ao aluno elementos de representação teatral, movimento e composição corporal no processo criativo como do conhecimento de si mesmo e estimula o trabalho em equipe. Essa prática inclui tanto em grupo quanto em individual, com isso tendo uma melhor improvisação e potencialidade.

O teatro em si ele já tende a tirar o melhor de cada ator em cena, seja em qualquer aspecto e as oficinas são como um "recheio", pois é através dela que obtemos resultados e desenvolvimento em pratica teatral e pessoal. E importante que oficinas de teatro sejam aplicadas, pois todo e qualquer desenvolvimento pode ser levado para vida pessoal do ator e em cena. Os minicursos oferecidos no Ciência em Cena alunos foram: técnicas vocais, jogos corporais e dança contemporânea.

Assim como comenta Taynna Oliveira sobre a oficina de Técnica Vocal ministrada no Ciência Cena.

Eu aprendi a dar uma entonação melhor a minha voz porque antes eu não falava muito alto. Então, depois da oficina participei de outra apresentação fora do QuíMistura e percebi que minha voz já estava mas posicionada. E ajudou porque eu falava muito alto com as pessoas, mas em palco falava muito baixo. Então parei de forçar a voz e ajudou bastante.

Esse é o relato da aluna do Centro de Educação Integrada Professor Eliseu Viana sobre a Oficina Técnica Vocal, que a mesma diz que atingiu o objetivo com a oficina tendo o melhor desenvolvimento e obtendo resultados positivos na sua voz. Por isso, e de tamanha importância que as oficinas sejam aplicadas em diversos âmbitos do teatro, o resultado pode ser claramente obtido.

No teatro QuíMistura foram feitas as seguintes oficinas, para obter o melhor preparo no desenvolvimento dos alunos para a apresentação no IX Ciência em Cena.

- Oficina de Voz: para melhor entonação da voz e compreensão dos ouvintes, feito com práticas de trava língua dentre outros.

- Oficina de Improviso: melhor desempenho para decorar texto e improvisação nas cenas com criação de personagens e resposta imediata com base nas perguntas.

- Oficina de Experimentos nos quais foram realizados os seguintes. Todos os experimentos foram feitos em laboratório com seus devidos materiais.

- Capilaridade

- $\mathrm{pH}$

- Palha de Aço

- Combustão

Os experimentos realizados foi em prol da participação do QuíMistura do IX Ciência em Cena, que ocorreu no período de Setembro de 2015. 


\section{Resultados e Discussões}

A combustão resume-se entre dois ou mais reagentes com grande energia na forma de exotérmica para que isso ocorra e é fundamental que tenha quatro fatores: calor, combustível, comburente e reação em cadeia. A combustão pode ser completa quando todos os átomos de carbono são oxidados formando $\mathrm{CO} 2$ e H2O, incompleta quando não há oxigênio suficiente produzindo monóxido de carbono e espontânea causada de maneira natural.

Com base nisso foi desenvolvido um questionário com seis perguntas relacionado combustão completa e incompleta e uma sobre o desenvolvimento do aluno no minicurso. Os alunos responderam por escrito o máximo que foi passado conhecimento sobre combustão, tanto na parte teórica como na prática e até mesmo aquilo que não compreenderam como o processo foi feito.

De acordo com a prática no Ciência em Cena, ao colocar o copo sobre a vela acessa por quer a chama se apaga? Experiências químicas feita nas atividades práticas em laboratório aprenderam que quando a chama se apaga não há oxigênio para que possa manter acesa. Nas apresentações das outras peças houve algum processo de combustão? Sessenta por centro dos alunos responderam foram sim, pois tiveram a compreensão de que combustão e a queima de algo (sólido, liquido ou gás).

Em uma das questões era pedido que e explique como ocorre o processo da palha de aço e por que há aumento da massa? Cerca de noventa por cento das respostas foram com base no texto decorado que tem o aumento da massa por causa do ar que foi fixado na combustão. Qual a função da parafina na vela? Setenta por centos dos alunos responderam que sua função e de manter a chama da vela acessa. Cite quatro experimentos que você observou nas peças teatrais durante o ciência em cena, cem por cento dos alunos responderam há mais do que foi pedido, a mais em comum foram aquelas que foram usado fogo como o de combustão no garrafão ou algo que muda de cor como a "tromba de elefante".

Quando identifica uma fumaça escura na vela, qual o processo que ocorre? Apenas vinte por centos dos alunos souberam identificar a combustão incompleta, e os outros setenta não souberam responder. Com o conhecimento no minicurso, teve algum avanço na prática teatral? Cem por cento dos alunos disseram sim, que houve melhoria como voz, corpo e personagem, resposta de alunos:

(1) com certeza! Contribuiu bastante para o avanço do personagem e para o ator, o estudo do corpo exponha se mais ainda a expressão em cena.

(2) sim! Melhorou bastante a minha voz, pude aprender varias técnicas, como impor a voz, saber o tom certo para falar.

(3) sim! Ajudou-me a ter mais conhecimento em relação ao meu corpo. 


\section{Conclusão}

Com base nas respostas dos alunos as que foram mais chamada atenção foram para a dos experimentos nas outras peças teatrais, muitos lembram o processo final após os experimentos, pois a prática e mais atrativa do que somente a teoria. A mais em comum dentre eles foram o experimento da "tromba de elefante" que e feito com peroxido de hidrogênio, detergente comum, corante e iodeto de potássio. E dissolvido o iodeto de potássio em um frasco, em uma proveta coloca-se o peroxido de hidrogênio, acrescentando o detergente e o corante agitando para misturar e por fim acrescenta a solução de iodeto de potássio produzindo grande quantidade de espuma.

Terminamos concluindo que a base de conhecimentos dos alunos no assunto especificado se deu mais pela decoração do texto da peça apresentado que foi a Historia Química de uma Vela. 


\section{Referencias Bibliográficas}

MENDES, D. O. Teatro Científico: a arte como divulgação da ciência Coreia, Coreia: um exercício de teatro científico. Especialização em Divulgação da Ciência, da Tecnologia e da Saúde, Museu da Vida/ Casa de Oswaldo Cruz/ Fundação Oswaldo Cruz, 34 p: 2010.

SARAIVA, C. C. Teatro Cientifico e ensino da química. Faculdade de Ciências, Faculdade de Ciências da Universidade do Porto, 172 p: 2007.

MOUNTINHO, Sofia. Ciência em Cena. Disponível em: <http://cienciahoje.uol.com.br/aloprofessor/intervalo/2013/04/ciencia-em-cena/?searchterm=None>. Acesso em: 30 de setembro de 2015.

MEDINA, M. N. Frankenstein: A Aproximação das ciências com alunos de ensino médio através do Teatro. Ensino de Ciências e Matemática, Colégio Pedro II / Departamento de Física/ UNED, Centro Federal de Ensino Tecnológico Celso Suckow da Fonseca - CEFET-RJ, 9 p: 2008.

BATALHA, R. R. M.; FALCONIERI, A. G. F.; SANTOS, A. G. D.; DI SOUZA, L.; OLIVEIRA, T. L.; FROTA, R. O. Teatro científico: Uma ferramenta para despertar o interesse em aprender Química. Universidade do Estado do Rio Grande do Norte, Departamento de Química, $6 \mathrm{p}$.

MARQUES, V.S.B.; FALCONIERI, A.G.F.; OLIVEIRA, A.D.; LIMA, E.L.F. Teatro Cientifico: Uma Proposta Metodológica para o Ensino de Química, Universidade do Estado do Rio Grande do Norte, Departamento de Química, 2014.

MOTIM, F. S. B.; SOUZA, I. L. N. Proposta Didática sobre divulgação cientifica: Química por meio do Teatro. Química, Universidade Federal do Paraná, 11 p: 2012.

CARMO, C. J.; SILVIA, M. V.; As técnicas teatrais em sala de aula. Disponível em: $<\mathrm{http}$ ///caixotedoteatro.blogspot.com.br/p/artigo-cientifico.html>. Acesso em: 30 de setembro de 2015.

SILVA, L. M.; BATALHA, R. R. M.; FALCONIERI, A. G. F.; DI SOUZA, L. FANATicos da Química: O teatro científico como ferramenta no ensino de química. Licenciatura em Química, Universidade do Estado do Rio Grande do Norte, 21 p: 2010.

COMBUSTAO, Disponível em: <http://www.cimi.com.br/Site/conceitos/Combustao.htm>. Acesso em: 30 de setembro de 2015.

LIRA, J. C. L. Combustão, Disponível em: <http://www.infoescola.com/reacoesquimicas/combustao/>. Acesso em: 30 de setembro de 2015. 